\title{
DE HOLLANDSCHE IJZEREN SPOORWEG-MAATSCHAPPIJ IN HET JAAR 1878.
}

In den vorigen jaargang van dit Tijdschrift (zie bl. 638) hebben wij medegedeeld, dat het voornemen bestond, om het gedeelte van den Staatsspoorweg Zaandam-Amsterdam in exploitatie te brengen. Nabij de Willemspoort werd te Amsterdam een personenhalte gebouwd en daarop den 15den Mei 1878 het gedeelte ZaandamAmsterdam in dienst gesteld. Vervolgens is een hulpstation in het Westerdok gemaakt en den 15 den October 1878 de dienst van den Staatsspoorweg en den Hollandsche spoorweg daarnaar overgebragt.

De Hollandsche IJzeren Spoorwegmaatschappij heeft (zie Economist 1874 , bl. 529) op zich genomen de exploitatie van de lijnen der Nederlandsch-Westfaalsche Spoorwegmaatschappij. Het gedeelte Zutphen-Winterswijk werd den 24sten Julij 1878 voor het publiek geopend. Op het einde van 1878 werden door de Hollandsche IJzeren Spoorweg-Maatschappij geëxploiteerd, primo haar eigen

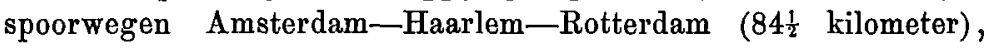
Haarlem-Uitgeest (18 kilometer), Amsterdam-AmersfoortUtrecht (64 kilometer), Amersfoort-Zutphen (58 $\frac{1}{2}$ kilometer) en het baanvak in het open havenfront te Amsterdam, dat gedeeltelijk aan de Maatschappij en gedeeltelijk aan den Staat behoort (5 kilometer); en secundo de Noord-Hollandsche Staatsspoorweg

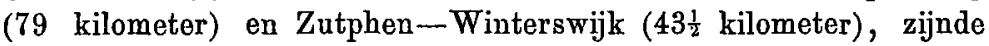
te zamen $352 \frac{1}{2}$ kilometer, waarvan 7 kilometer gemeenschappelijk.

De exploitatie-rekening van de eigen lijnen der Maatschappij benevens van Zaandam-Amsterdam en Zutphen-Winterswijk vormen één geheel, zoodat moeijelijk met juistheid is aan te geven hoeveel winst en verlies de Maatschappij op ieder der lijnen gehad heeft. Het gedeelte Zaandam-Amsterdam, hoewel Staatsspoor, is hierbij gevoegd uithoofde van de bijzondere voorwaarden van exploitatie, die wij verleden jaar hebben medegedeeld in dit Tijdschrift, bl, 638 . 
Wanneer men den gedrukten toestand van handel en nijverheid in aanmerking neemt, dan was de uitkomst over 1878 bevredigend.

Het vervoer van reizigers bedroeg op Amsterdam-Rotterdam en Haarlem-Uitgeest $f 88.000$ meer dan in het vorige jaar, en op den Oosterspoorweg $f 70.000$ meer. Ook het goederenvervoer nam toe, terwijl het veevervoer vermeerderde op den Oosterspoorweg on verminderde tusschen Amsterdam en Rotterdam, ten gevolge van den uitvoer over Amsterdam, in plaats van over Rotterdam.

De telegraaf-ontvangsten waren $f 680$ lager dan in het vorige jaar.

Volgens de exploitatie-rekening over 1878 bedroegen de ontvangsten op de eigen lijnen der Maatschappij on op ZaandamAmsterdam en Zutphen-Winterswijk:

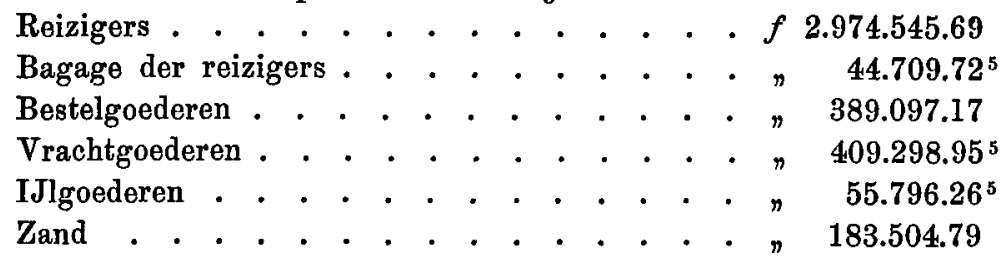

Diversen voor verkoop van drukwerken, bewaargelden, bestelloonen, enz. . . . . . . . $n \quad 24.994 .55$

Paarden, vee en rijtuigen . . . . . . . . $n 78.233 .10^{5}$

Brievenvervoer . . . . . . . . . . ” $23.206 .36^{5}$

Telegraaf . . . . . . . . . . . . . " $6.897 .87^{5}$

Diversen, als opbrengst van eigendommen, huur van woningen, buffetten, enz. . . . . . . n 87.106 .94

Zandtreinen ten behoeve der exploitatio $\cdot \cdot \frac{n}{f 4.291 .635 .76}$

Het totaal der opbrengsten bedroeg in 1878: AmsterdamHaarlem-Rotterdam $f$ 2.682.369.40 tegen $f 2.522 .041 .44$ in 1877 . Haarlem-Uitgeest $f 214.605 .55^{5}$ tegen $f 213.077 .52$ in 1877 .

Amsterdam-Zaandam van af $15 \mathrm{Mei} f 13.434 .98^{5}$.

Amsterdam-Zutphen-Utrecht $f 1.345 .839 .31^{5}$ tegen $f 1.309 .601 .87^{5}$ in 1877 .

Zutphen-Winterswijk van af 24 Julij $f 35.386 .50^{5}$.

Per kilometer en per jaar is de opbrengst dezer lijnen achtereenvolgens $f 31.744, f 11.922, f 2.239, f 10.767$ en $f 1.815$. Over de verschillende baanvakken bedroeg de opbrengst van het vervoer per jaar kilometer : 
1877.

\begin{tabular}{|c|c|c|}
\hline Amsterdam-Haarlem . & $f 34.051$ & $f 35.785$ \\
\hline Haarlem-Leiden . & $\eta 19.760$ &, 20.573 \\
\hline Leiden-den Haag . & n 27.205 & 8.515 \\
\hline den Haag-Rotterdam. & 36.918 & 38.679 \\
\hline Amsterdam-Amersfoort & 14.866 & n 16.214 \\
\hline Amersfoort-Zutphen . & » 3.756 & $\pi 4.895$ \\
\hline Hilversum-Utrecht & 8.450 & 8.818 \\
\hline
\end{tabular}

Hoewel de opbrengst Amersfoort-Zutphen, lang 60 kilometers, eenigzins is toegenomen, blijft die toch nog zeer gering. Wij vermoeden, dat de exploitatie ongeveer $f 3000$ per jaar kost, zoodat nog geen $f 2000$ per kilometer overschiet, terwijl voor de renten van het kapitaal van aanleg minstens $f 3000$ moet gerekend worden. Op het gedcelte Amersfoort-Zutphen zal de Maatschappij dus wel een $f 60.000$ 's jaars verliezen.

De uitgaven voor de eigen lijnen en Zutphen-Winterswijk te zamen bedroegen in 1878:

Onderhoud van den weg . . . . . . . . $f$ 473.902.85

Buitengewone werken . . . . . . . . . ” 22.704.095

Onderhoud der stations en workplaats . . . n 95.150 .35

Directie en toezigt der baan . . . . . . . " 40.163.25

Onderhoud der locomotieven, wagens, enz. . n 268.023 .99

Directie der werkplaats en der tractie . . . ” 17.268 .30

Daggelden van machinisten, stokers, brandstoffen, smeer, water voor locomotieven, rangeerdienst, enz. . . . . . . . . . . . . . . . ${ }^{n} 341.181 .52^{\mathrm{s}}$

Traktementen voor de inspecteurs, ambtenaren op de stations, opzigters, conducteurs, wachters, enz. . . . . . . . . . . . . " 493.545.91

Kosten der goederen-, hulp- en bestelkantoren, $218.442 .45^{5}$

Traktementen van de ambtenaren op de controle en voor de handelszaken . . . . . . . n $\mathbf{7 1 . 9 0 3 . 6 6}^{5}$

Raad van administratie . . . . . . . . . n 18.525 .00

Traktementen van de administrateurs en andere beambten, benevens kosten van de bureaux, belastingen, enz. . . . . . . . . $\frac{n 147.633 .29^{\mathrm{s}}}{f 2.208 .444 .69^{5}}$

De exploitatiekosten hebben 52 pCt. van de ontvangsten bedragen. In de Reservekas is het maximum van één millioen bereikt en aanwezig.

De opbrengst van den Noord-Hollandschen Staatsspoorweg 
(van Helder tot Zaandam) bedroeg in $1878 f 395.869 .25$ tegen $f 401.639 .22$ in 1877. Deze opbrengst was aldus verdeeld.

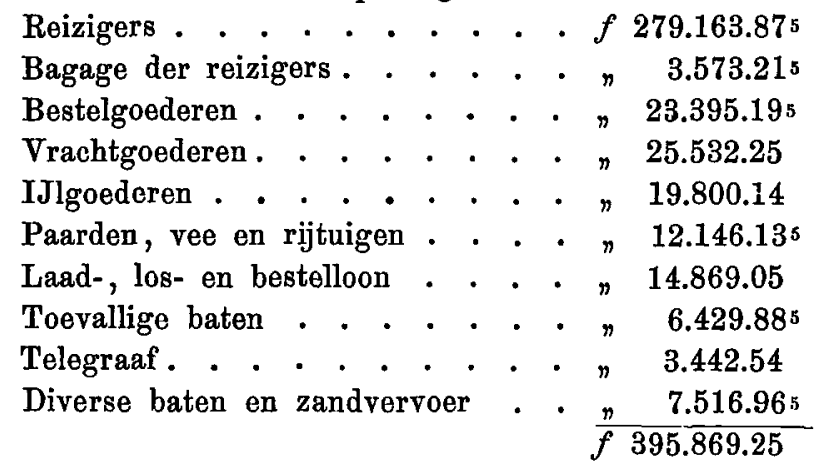

De opbrengst per kilometer van deze lijn bedroeg $f 5576$. Het meest bragt op Alkmaar-Uitgeest $f 7691$ en het minst UitgeestZaandam $f$ 2889. Deze sommen blijven steeds klein, en zullen waarschijnlijk nog verminderen, als de stoombooten der Maatschappij Nederland niet meer van het Nieuwe Diep, maar van Amsterdam vertrekken. Hoewel, zooals wij reeds hiervoor gezegd hebben, het gedeelte Zaandam-Amsterdam, lang 10 kilometer, niet onder deze ontvangsten begrepen is, zoo is ook daar het vervoer uiterst gering en bedroeg in 1878 , dat is van $15 \mathrm{Mei}$ tot ultimo December, per kilometer slechts $f 1355$, dus nog niet genoeg, om de exploitatiekosten te dekken.

De uitgaven beliepen $f 335,286.52$ in 1878 tegen $f 309,220,65^{5}$ in 1877 ; deze meerdere uitgaven werden vooral veroorzaakt door de grootere kosten aan den weg on het station Amsterdam omdat, voor zoover het onderhoud betreft, hierbij in 1878 is gekomen het gedeelte Zaandam-Amsterdam. Daarenboven is de spoorweghaven te Nieuwe Diep uitgediept. Het onderhoud betreft in 1878 de lijn Helder-Amsterdam on in 1877 Helder-Zaandam.

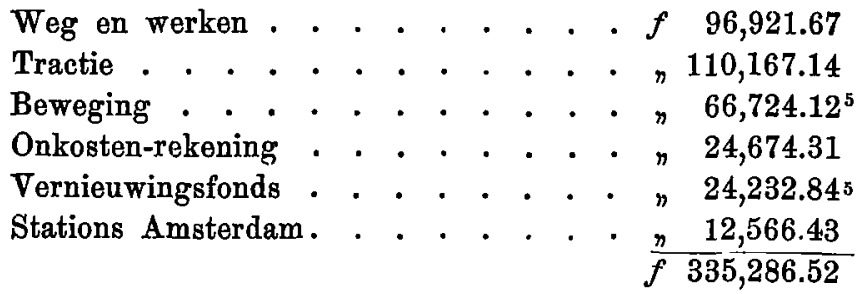

De exploitatiekosten bedroegen $92 \mathrm{pCt}$. tegen $77 \mathrm{pCt}$. in 1877 . Van de opbrengst moet worden uitgekeerd aan den Staat der Nederlanden $f 102,065.75$. De Maatschappij verloor in 1878 op de 
exploitatie van den Noord-Hollandschen Staatsspoorweg $f 28,355.53^{5}$. Dat de schatkist er ook geen voordeel van trekt, blijkt als men bedenkt, dat alleen het gedeelte van den Helder tot de Voorzaan heeft gekost $8 \frac{1}{2}$ millioen.

De Maatschappij moet aan den Staat betalen de helft der kosten van aanleg van het groote station te Rotterdam; hiervan is op afrekening reeds betaald één millioen gld. Op de balans kwam sinds jaren een post voor van bijna 60 mille voor kosten van aanleg van den spoorweg Leiden-Woerden, die de Hollandsche spoorwegmaatschappij indertijd zelf had willen maken. Op dit bedrag is 50 mille afgeschreven; dit was noodig nu door een andere Maatschappij is aangelegd de lijn Leiden-Woerden, die door de Nederlandsche Rijnspoorwegmaatschappij sinds 15 October 1878 geëxploiteerd wordt. In ons verslag over 1877 (zie Economist 1878 , bl. 640) voorspelden wij, dat de exploitatie van het gedeelte Zutphen-Winterswijk nadeel zou opleveren. Dit is nog grooter dan wij vreesden. Berekend over een geheel jaar is de opbrengst per kilometer $f 1815$. Gesteld de uitgaven voor de exploitatie bedragen $f 2415$ per kilometer en de huur die de NederlandschWestfaalsche spoorwegmaatschappij krijgt (zie Economist 1874, bl. 530) $f 600$, dan is dit een uitgaaf van $f 3015$ tegen een ontvangst van $f 1815$, dus een nadeelig verschil van $f 1200$ per kilometer of over $43 \frac{1}{2}$ kilometer $f 52.200$. Hierbij moet men in aanmerking nemen, dat Zutphen-Winterswijk voedt den Oosterspoorweg en in beter toestand komt, als de lijn doorgetrokken is tot het kolenvervoer.

Toen den $15^{\mathrm{n}}$ October 1878 het station in het Westerdok te Amsterdam zou worden geopend, meende men, dat dit station met dat in het Oosterdok zoodanig door rails zou verbonden worden, dat al de reizigers en goederen van het eene station naar het andere per trein zouden vervoerd kunnen worden. Reeds was één stel rails tusschen de beide stations gelegd, en maakten de Staatsspoorwegingenieurs toebereidselen, om een tweede stel rails te leggen. $B i j$ het vaststellen van de vertrekuren der winterdienst werd dan ook van de veronderstelling uitgegaan, dat de personen en goederen per trein vervoerd zouden worden. Plotseling maakte de Minister van Waterstaat, Handel en Nijverheid bezwaar, om een tweede stel rails te leggen. In de memorie van antwoord over het wetsontwerp tot vaststelling der begrooting van uitgaven voor den aanleg van Staatsspoorwegen over 1879 antwoordde genoemde Minister aan de Eerste Kamer der Staten-Generaal op den wensch 
om de beide stations te $\Lambda$ msterdam zoodanig te verbinden, dat de reizigers en goederen per trein van het eene station naar het andere zoude vervoerd worden:

"Bij eene overeenkomst, onder dagteekening van 25 Junij 1875, n door den afgetreden Minister van Binnenlandsche Zaken met de "Nederlandsche Rijnspoorwegmaatschappij gesloten, is aan deze $n$ het medegebruik der spoorwegwerken te Amsterdam tusschen " de brug vóór de Eenhoornsluis, de Stads Rietlanden en de St. ${ }_{n}$ Anthoniedijk toegestaan op dezelfde voorwaarden, als dit vroeger "voor de dienst op den Oosterspoorweg was overeengekomen. "Dien tengevolge kan, daar de omvang van het voorloopig em„placement in het Westerdok een geheel overbrengen der dienst "van den Rijnspoorweg daar henen niet gedoogt, ook het mede"gebruik der tijdelijke stationsinrigting niet ten behoeve van ${ }_{n}$ den Oosterspoorweg worden toegestaan, voor dat daaromtrent " met de Nederlandsche Rijnspoorwegmaatschappij zal zijn overeen"gekomen. De voorwaarden, waarop dit zou kunnen geschieden, "zijn aan de Nederlandsche Rijnspoorwegmaatschappij medege"deeld. Zoodra met haar is overeengekomen, zal aan den geuiten "wensch worden voldaan."

Wij hebben de bedoelde overeenkomst van 25 Junij 1875 nagelezen in het werk: Verzameling van wetten, besluiten enz. betreffende de spoorwegen in Nederland door Jhr. E. van Cilters en J. C. A. van Roosendaal, uitgegeven te's Gravenhage bij de Gebroeders van Cleef, maar wij kunnen niet inzien, dat or bezwaar bestaat, om aan de Hollandsche spoorwegmaatschappij te vergunnen om, evenals zij thans met de goederen doet, ook de reizigers per trein te vervoeren van het station in het Oosterdok, naar dat in het Westerdok $\left({ }^{*}\right)$.

In het verslag der Directie vinden wij met geen onkel woord melding gemaakt van onderhandelingen of besprekingen met de Regering over de verlenging voor het gedeelte RotterdamAmsterdam der concessie, die eindigt $31 \mathrm{Mei}$ 1880. De Staat kan dit gedeelte spoorweg alsdan tegen ongeveer 15 millioen gld. overnemen. Wanneer men bedenkt, dat de Maatschappij over 1878 zuiver ongeveer 13 ton van dezen spoorweg heeft getrokken, zou zulks een groot nadeel voor de Maatschappij zijn. Zeer globaal berekend,

(*) $\mathrm{Na}$ het schrijven vau dit stuk vernemen wij met genoegen, dat met ingang van 15 Mei 1879 een doorgand verkeer zal geopend worden tusschen de beide stations te Amsterdam. 
zou ieder der 15000 aandeelen 30 gld. minder per jaar krijgen bij naasting. Zeer verwondert het ons daarom dat de Directie met geen woord van deze hoogst gewigtige zaak spreekt.

Den 31n Maart 1879 had eerst een buitengewone en daarna de gewone jaarlijksche vergadering van aandeelhouders te Amsterdam plaats.

Er waren 102 aandeelen vertegenwoordigd, uitbrengende 65 stemmen. In de buitengewone vergadering werd bepaald, dat de gewone jaarlijksche vergadering, waarin de balans wordt vastgesteld, niet meer in de laatste week van Maart, maar van Mei zal gehouden worden. Het is trouwens onmogelijk vóór dien tijd een behoorlijke rekening op te maken, sinds de Hollandsche IJzeren Spoorwegmaatschappij in directe verbinding met het buitenland staat. De rekening en de balans werden goedgekeurd en het dividend bepaald op $f 61.75$ per aandeel van $f 1000$, waarvan in October reeds een voorloopig dividend van $f 20$ was betaald. Wanneer men bedenkt, dat het dividend in het vorige jaar was $f 58$ en in 1878 de handel en nijverheid zeer waren gedrukt, dan is de uitkomst zeer goed.

Wij hebben reeds met een enkel woord er op gewezen, dat de exploitatie van den Oosterspoorweg, en van Zutphen-Winterswijk nadeelige finantieele resultaten gaven; gaarne stemmen wij toe, dat die lijnen nog in geen normalen toestand zijn. De vraag hebben wij ons gesteld, of de Maatschappij niet voordeeliger voor hare aandeelhouders zou gehandeld hebben, door de Oosterspoorweg niet te maken, en zich alleen te bepalen tot de exploitatie harer eigen lijnen Amsterdam-Haarlem-Rotterdam en HaarlemUitgeest, benevens van den Noord-Hollandschen Staatsspoorweg. Het is hoogst moeijelijk een juiste rekening te maken; het aandeelen-kapitaal is uitgebreid, leeningen zijn gesloten, de kosten van installatie, enz. moeten in rekening worden genomen, enz. Uit het finantieel verslag blijkt, dat in 1873 de eerste groote leening is uitgegeven; neemt men daarom de ontvangsten over 1872 dan bedroegen die globaal in dat jaar op RotterdamHaarlem-Amsterdam en Haarlem-Uitgeest 21 ton en in 1878 bijna 29 ton, gevende dus een meerdere zuivere inkomst van 4 ton. Het dividend bedroeg over 1872 per aandeel $f 65$, terwijl het aandeelen-kapitaal was groot $f 9.100 .000$. Ware het kapitaal nog zoo klein, dan zou over 1878 ongeveer zijn uitgedeeld $f 84$ per aandeel, in plaats van $f 61.75$, zooals thans. Hoewel deze eijfers zeer globaal zịjn, en tot gegronde kritiek aanleiding kunnen 
geven, zoo volgt er toch uit, dat de uitbreiding der lijnen door de Maatschappij ongunstige finantieele resultaten voor de aandeelhouders heeft gegeven, en deze beter zouden gediend zijn geweest, als de Maatschappij zich bepaald had tot de exploitatie harer oude spoorweglijn. Meerdere spoorwegmaatschappijen hebben den dwaalweg bewandelt, om hun spoorwegnet uit te breiden, tot groot nadeel van de aandeelhouders.

J. J. VAN KERKWIJK. 